\title{
Quantitative analysis of 33 benzodiazepines, metabolites and benzodiazepine-like substances in whole blood by liquid chromatography-(tandem) mass spectrometry
}

\author{
B.E. Smink ${ }^{\mathrm{a}, *}$, J.E. Brandsma ${ }^{\mathrm{a}}$, A. Dijkhuizen ${ }^{\mathrm{a}}$, K.J. Lusthof ${ }^{\mathrm{a}}$, \\ J.J. de Gier ${ }^{b}$, A.C.G. Egberts ${ }^{\mathrm{b}}$, D.R.A. Uges ${ }^{\mathrm{c}}$ \\ a Department of Toxicology, Netherlands Forensic Institute, P.O. Box 3110, 2280 GC Rijswijk, The Netherlands \\ ${ }^{\mathrm{b}}$ Department of Pharmacoepidemiology and Pharmacotherapy, Utrecht Institute for Pharmaceutical Sciences, \\ P.O. Box 80082, 3508 TB Utrecht, The Netherlands \\ ${ }^{c}$ Department of Pharmacy, Toxicology and Forensic Medicine, State University and University Hospital Groningen, \\ P.O. Box 30.001, 9700 RB Groningen, The Netherlands
}

Received 20 November 2003; accepted 24 March 2004

\begin{abstract}
A quantitative method using high-performance liquid chromatography-mass spectrometry (LC-MS, ion trap) after matrix supported liquid-liquid extraction is described for the simultaneous determination in whole blood of 33 benzodiazepines including metabolites and benzodiazepine-like substances. The limits of detection (LOD) range from 0.0001 to $0.0126 \mathrm{mg} / \mathrm{l}$. Linearity is satisfactory for all compounds. The extraction recoveries for the benzodiazepines in whole blood are between 60 and 91\%, desmethyldiazepam, OH-bromazepam and brotizolam excepted. Selectivity, accuracy and precision are satisfactory for clinical and forensic purposes.
\end{abstract}

(C) 2004 Elsevier B.V. All rights reserved.

Keywords: Benzodiazepines; Whole blood analysis; Drugs and driving

\section{Introduction}

Benzodiazepines are substances with a broad range of therapeutic uses; they have sedative-hypnotic, muscle relaxant, anxiolytic, anticonvulsant but also addictive effects $[1,2]$. Since the first benzodiazepines were introduced to the market in 1960, there has been an evolution in the development of these drugs toward compounds with less active metabolites, shorter action and faster clearance. There are more than twenty benzodiazepines in use in The Netherlands [3]. The benzodiazepines are relatively safe drugs with mild side effects. However, elderly patients are at increased risk of benzodiazepine induced psychomotor impairment (broken hips by falling [4]) and patients suffering a lung dis-

\footnotetext{
* Corresponding author. Tel.: +31 704135 772; fax: +31 704135452 .

E-mail address: b.smink@nfi.minjus.nl (B.E. Smink).
}

ease may be at increased risk of respiratory depression [5]. The use of benzodiazepines is also associated with an increased risk of a road-traffic accident [6]. Large doses are rarely fatal unless other drugs are taken concomitantly. Due to their wide variety of uses and their relative safety, benzodiazepines and benzodiazepine-like substances (e.g. zopiclone) are frequently used. Analysis of benzodiazepines, their active metabolites and benzodiazepine-like substances in blood samples may be indicated in a lot of forensic cases such as driving under the influence of drugs, cases of date-rape or violent crime and cases of unknown causes of death. In The Netherlands, autopsy cases excluded, samples are collected by physicians and shipped by mail to The Netherlands Forensic Institute in containers with sodium fluoride as preservative, which makes it impossible to obtain plasma or serum by centrifuging. As a consequence, the analytical methods must be suitable for the analysis of whole blood samples. The 
large number of possibly present benzodiazepines, metabolites and benzodiazepine-like substances must be considered. Screening methods involving high-performance liquid chromatography with diode-array detection (HPLC-DAD) or gas chromatography in combination with mass spectrometry (GC-MS) may often be not sensitive enough for forensic or clinical purposes [7].

Until now, we have used two analytical methods to analyse benzodiazepines, metabolites and benzodiazepine-like substances in blood. One method, using HPLC-DAD to determine a limited number of benzodiazepines with medium to high blood concentrations in the therapeutic range such as diazepam and oxazepam, and another method, using LC-MS to analyse benzodiazepines with low (therapeutic) blood concentrations like flunitrazepam. The aim of this study was to develop a new method that is suited for all available benzodiazepines with low limits of detection (LOD). In this article, we present a validated method that is capable of analysing 33 benzodiazepines, metabolites and benzodiazepine-like substances in whole blood samples by using LC in combination with alternate MS and MS-MS detection. The selection of the tested substances and metabolites is based on the availability in The Netherlands and the pharmacological activity $[1,3]$.

\section{Experimental}

\subsection{Chemicals and reagents}

Chemicals were obtained from Alltech (State College, PA 16801 USA: norchlordiazepoxide), Aventis Pharma (Hoevelaken, The Netherlands: clobazam, desmethylclobazam, loprazolam), Boehringer Ingelheim (Alkmaar, The Netherlands: brotizolam), Bufa (Uitgeest, The Netherlands: diazepam, flunitrazepam, lorazepam, oxazepam, temazepam), Cerilliant (Austin TX, USA: alprazolam, hydroxy-alprazolam, bromazepam, aminoflunitrazepam, norflunitrazepam, flurazepam, desalkylflurazepam, lormetazepam, midazolam, hydroxy-midazolam, desmethyldiazepam, triazolam, hydroxy-triazolam), Hoffman-La Roche (acetamidonitrazepam, chlordiazepoxide, demoxepam, OH-ethylflurazepam, desmethylmedazepam), Lorex Synthelabo (Maidenhead, UK: zolpidem), Roche (Almere, The Netherlands: hydroxy-bromazepam, acetamidoclonazepam, aminoclonazepam) and Sigma-Aldrich Chemie B.V. (Zwijndrecht, The Netherlands: clonazepam, nitrazepam, zopiclone).

Stock solutions were prepared by dissolving $10 \mathrm{mg}$ (accurately weighed) of the compound in $10 \mathrm{ml}$ of methanol. These solutions were stored at $-20^{\circ} \mathrm{C}$. Working standards were diluted in methanol. The concentrations of the working standards were approximately $0.1 \mathrm{mg} / \mathrm{l}$ methanol for all compounds.

The solution of the internal standard (methylbromazepam), was obtained from Chromsystems (Munchen,
Germany). Solvents used were methanol (Rathburn, Brunschwig Chemie B.V., Amsterdam, The Netherlands, HPLCgrade), acetonitrile (Merck, VWR Amsterdam, The Netherlands, HPLC-grade Lichrosolv), ammonia solution 25\% $(\mathrm{m} / \mathrm{v})$ (Merck, pro analyse), formic acid (Merck, pro analyse) and $t$-butylmethylether (Merck, Suprasolv). The ammonia solution (approximately $0.005 \mathrm{M}$ ) was made up by diluting $0.75 \mathrm{ml}$ ammonia $25 \%$ (m/v) to $2000 \mathrm{ml}$ with distilled water. The formic acid solution (approximately $0.006 \mathrm{M}$ ) was made up by diluting $0.45 \mathrm{ml}$ formic acid $100 \%$ (v/v) to $2000 \mathrm{ml}$ with distilled water.

ChemElut ${ }^{\circledR}$ cartridges (Varian, Middelburg, The Netherlands: pre-buffered, $\mathrm{pH}$ 9) were used for the sample preparation of whole blood.

Human blood was obtained after informed consent, from donors of the blood bank in Leiden and screened for the presence of benzodiazepines by HPLC-DAD and LC-MS(MS).

\subsection{Sample preparation}

Blood samples, spiked with all compounds and $50 \mu$ lof the internal standard solution, were applied onto the ChemElut ${ }^{\circledR}$ cartridges, followed by $1.5 \mathrm{ml}$ water. The samples were eluted from the cartridges with $4 \mathrm{ml} t$-butylmethylether and after a pause of $20 \mathrm{~min}$ with another $2 \times 4 \mathrm{ml} t$-butylmethylether. Evaporation of the eluate was performed by using an Automatic Environmental Speedvac AES2000 (Savant) with drying rate "high" $\left(50^{\circ} \mathrm{C}\right)$ for $35 \mathrm{~min}$. The residue was redissolved in $100 \mu$ l methanol:water (40:60).

\subsection{Equipment}

The LC-MS system consisted of a TSP Spectra SYSTEM (Finnigan, Breda, The Netherlands), including a SN4000 controller, a vacuum degasser (SCM 1000), a pump (P4000) and an auto sampler (AS3000), connected to an ion trap mass spectrometer (LCQ, Finnigan).

In order to determine the influence of the interface on the sensitivity, standards $(1000 \mathrm{mg} / \mathrm{l}$ diluted in acetonitrile:water $=10: 90$ ) were analyzed by using atmospheric pressure chemical ionization (APCI)-LC-MS as well as ESI-LC-MS. From all tested benzodiazepines, the signal-to-noise ratios from the different interfaces were compared. The interface used in the final procedure is atmospheric pressure chemical ionization.

For the analysis of benzodiazepines, conditions were optimized. Chromatographic data were acquired and processed using X-calibur ${ }^{\mathrm{TM}} 1.2$ software (Finnigan).

\subsection{Chromatography}

In order to optimize the separation, two different column materials and four different solvents were tested. Eight column-solvent combinations were tested by analysing standards in methanol in order to achieve the best separation of the compounds. The columns tested were the Xterra MS C-18 (150 mm $\times 2.1 \mathrm{~mm}, 3.5 \mu \mathrm{m}$ PS, Waters $)$ and the 
Xterra RP C-18 $(150 \mathrm{~mm} \times 2.1 \mathrm{~mm}, 3.5 \mu \mathrm{m}$ PS, Waters $)$. The injection volume was $50 \mu$ l. Chromatography was performed by using a flow-rate of $0.2 \mathrm{ml} / \mathrm{min}$ and a column temperature of $30^{\circ} \mathrm{C}$. The linear gradients used were acetonitrile/ammonia approximately $0.005 \mathrm{M}(\mathrm{pH} 10,25-65 \%$ (v/v) acetonitrile), acetonitrile/formic acid approximately $0.006 \mathrm{M}$ $(\mathrm{pH} \mathrm{3,25-60 \%} \mathrm{(v/v)} \mathrm{acetonitrile),} \mathrm{methanol/ammonia} \mathrm{ap-}$ proximately $0.005 \mathrm{M}(\mathrm{pH} 10,45-90 \%(\mathrm{v} / \mathrm{v})$ methanol) and methanol/formic acid approximately $0.006 \mathrm{M}$ (pH 3, 30-60\% $(\mathrm{v} / \mathrm{v})$ methanol).

The optimized method used a Xterra MS C-18 column $(150 \mathrm{~mm} \times 2.1 \mathrm{~mm}, 3.5 \mu \mathrm{m}$ PS, Waters, Etten-Leur, The Netherlands). The gradient used for this LC-MS(MS) method is methanol/formic acid approximately $0.006 \mathrm{M}(\mathrm{pH}$ $3,30-60 \%(\mathrm{v} / \mathrm{v})$ methanol). The time intervals were $t=$ $0-5 \min (30-40 \%(\mathrm{v} / \mathrm{v})$ methanol), $t=5-25 \min (40-50 \%$ $(\mathrm{v} / \mathrm{v})$ methanol), $t=25-30 \mathrm{~min}(50-60 \%$ (v/v) methanol), $t$ $=30-35 \mathrm{~min}(60 \%(\mathrm{v} / \mathrm{v})$ methanol), $t=35-36 \mathrm{~min}(60-30 \%$ $(\mathrm{v} / \mathrm{v})$ methanol), $t=36-45 \mathrm{~min}(30 \%$ (v/v) methanol). The runtime was $45 \mathrm{~min}$, including a re-equilibration time of $10 \mathrm{~min}$.

\subsection{Mass spectrometry}

In order to detect benzodiazepines with low as well as high concentrations, the mass spectrometer acquires data alternately in MS (full scan) and MS-MS (product ion scan) mode. Daughter spectra of compounds analysed by MS-MS were obtained from the parent (molecular) ions or from a suitable fragment ion, by collisionally activated dissociation in the ion trap, using a collision energy of 30-50\%, depending on the substance (see Section 3.2).

Due to restrictions of the equipment in MS-MS mode concerning the number of scans per segments, it was not possible to use the MS-MS mode for all tested substances. The MS-MS product ion scan mode was used for the benzodiazepines with low concentrations and for benzodiazepines that co-elute. The alternate detection mode reduces the sensitivity of the detection. Therefore, the sensitivity was optimised by dividing the chromatographic run into segments. The segments were chosen in such a way that each contained a small number of benzodiazepines at low concentrations. The choice of the segments allows for small fluctuations in the retention times.

The final aquisition mode used MS detection for 15 substances and MS-MS detection for 21 substances, including the internal standard. The compounds were identified by the presence of the characteristic ions, listed in Table 1.

\subsection{Assay validation}

Validation of the assay included the lower limit of detection (LOD), the lower limit of quantification (LOQ), extraction recovery, linearity, specificity, precision and accuracy. The limit of detection was estimated at a signal-to-noise ratio equal to three in spiked whole blood. The limit of quantifica- tion was calculated for a signal-to-noise ratio of 10. Extraction recovery, expressed as a percentage, was determined by assaying spiked blood samples 10 times at a concentration level of $1.0 \mathrm{mg} / \mathrm{l}$. The extraction recovery was determined by comparing the peak heights of extracted blood samples with the peak heights of standards prepared in methanol. Linearity was estimated by assaying calibration curves consisting of a blank blood sample and 10 spiked blood samples $(0.005$; $0.01 ; 0.02 ; 0.05 ; 0.1 ; 0.2 ; 0.5 ; 1.0 ; 2.0 ; 5.0 \mathrm{mg} / \mathrm{l})$. Linear regression has been used to estimate the slopes and the intercepts. Deviation from linearity was investigated by consecutively including an extra datapoint in the calibration curve and performing linear regression. Non linearity was concluded when the slope differed by more than $20 \%$. Accuracy was estimated by analysing a quality control serum sample ( $n$ =6), spiked with oxazepam, temazepam, nordazepam and diazepam, obtained from the KKGT (Association for Quality Assessment in Therapeutic Drug Monitoring and Clinical Toxicology, The Hague, The Netherlands). No quality control samples were available to estimate the accuracy of all the tested substances in whole blood. The concentrations of the analytes were calculated using calibration curves in whole blood. Intra-day precision was determined by the analysis of the quality control serum sample $(n=6)$ and spiked blood samples at three concentration levels (Table $4, n=10$ ). The precision was expressed as the relative standard deviation (RSD).

\section{Results}

\subsection{Chromatography}

Eight different column material-solvent combinations were tested to achieve the best separation. The methanol/formic acid gradient in combination with the Xterra MS C-18 $150 \mathrm{~mm} \times 2.1 \mathrm{~mm}, 3.5 \mu \mathrm{m}$ PS resulted in the best separation and was selected. Fig. 1 shows the overlaid ion chromatograms of the tested benzodiazepines and benzodiazepine-like substances. A run of $45 \mathrm{~min}$, including a re-equilibration time of $10 \mathrm{~min}$ was selected.

\subsection{Mass spectrometry}

Although the interface (ESI or APCI) was not optimal for each substance, satisfactory sensitivities were obtained for all compounds by using the APCI interface. For APCI, optimal conditions were found to be vaporizer temperature, $400^{\circ} \mathrm{C}$; discharge current, $4 \mu \mathrm{A}$; capillary voltage, $45.00 \mathrm{~V}$; capillary temperature $150^{\circ} \mathrm{C}$. Table 1 shows the ratio $\mathrm{S} / \mathrm{N}$ (using APCI): $\mathrm{S} / \mathrm{N}$ (using ESI) ratios at a concentration of $10 \mathrm{mg} / \mathrm{l}$ using ESI and APCI sources and the parameters for the APCI-LC-MS(MS) method. For the compounds analysed by MS, retention time, MS molecular ion, MS fragment ions and scan range are presented. For the compounds analysed by MS-MS, retention time, MS molecular ion, MS-MS 
Table 1

Parameters for the LC-MS(MS) method

\begin{tabular}{|c|c|c|c|c|c|c|c|c|c|c|c|c|}
\hline \multirow{2}{*}{$\begin{array}{l}\text { Compound } \\
\text { Aminoclonazepam }\end{array}$} & \multirow{2}{*}{$\begin{array}{l}\text { Comparison of the } \\
\text { sources ratio S/N } \\
\text { (APCI):S/N (ESI) } \\
4.2\end{array}$} & \multirow{2}{*}{$\begin{array}{l}\begin{array}{l}\text { Retention } \\
\text { time } \\
(\mathrm{min})\end{array} \\
5.64\end{array}$} & \multirow{2}{*}{$\begin{array}{l}\text { MS } \\
\text { molecular } \\
\text { ion }\end{array}$} & \multirow{2}{*}{$\begin{array}{l}\begin{array}{l}\text { Acquisition } \\
\text { mode }\end{array} \\
\text { MS-MS }\end{array}$} & \multirow{2}{*}{$\begin{array}{l}\text { MSMS } \\
\text { precursor/parent } \\
\text { ion }\end{array}$} & \multirow{2}{*}{ 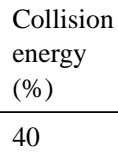 } & \multicolumn{4}{|c|}{ MS or MS-MS product ions } & \multirow{2}{*}{$\begin{array}{l}\text { Scan range } \\
(\mathrm{m} / \mathrm{z})\end{array}$} & \multirow{2}{*}{$\begin{array}{l}\begin{array}{l}\text { MS-MS } \\
\text { segment }^{\mathrm{a}}\end{array} \\
1\end{array}$} \\
\hline & & & & & & & 222 & 121 & & & & \\
\hline Acetamidonitrazepam & 5.8 & 6.77 & 294 & MS-MS & 207 & 46 & 266 & 163 & & & $80-500$ & $1+2$ \\
\hline 7-Aminoflunitrazepam & 2.5 & 7.90 & 284 & MS-MS & 264 & 42 & 256 & 163 & & & $75-500$ & $1+2$ \\
\hline Flurazepam & 0.4 & 9.91 & 388 & MS-MS & 315 & 48 & 317 & 288 & 143 & & $105-500$ & $1+2$ \\
\hline Loprazolam & 1.7 & 9.91 & 465 & MS-MS & 408 & 48 & 381 & 300 & & & $125-500$ & $1+2$ \\
\hline Acetamidoclonazepam & 3.3 & 10.04 & 328 & MS-MS & 292 & 46 & 241 & 205 & & & $90-500$ & 2 \\
\hline OH-midazolam & 1.1 & 15.78 & 342 & MS-MS & 324 & 36 & 313 & 203 & & & $90-500$ & $2+3$ \\
\hline Bromazepam & 2.7 & 17.16 & 316 & MS-MS & 288 & 38 & 261 & 209 & & & $85-500$ & $3+4$ \\
\hline OH-Bromazepam & 1.5 & 18.33 & 332 & MS-MS & 314 & 32 & 286 & 275 & & & $90-500$ & $3+4$ \\
\hline Internal standard & n.d. & 18.75 & 330 & MS-MS & 302 & 42 & 273 & 223 & 194 & & $90-500$ & $3+4$ \\
\hline$N$-Desmethylflunitrazepam & 4.8 & 19.15 & 300 & MS-MS & 254 & 42 & 272 & 214 & 176 & & $80-500$ & $4+5$ \\
\hline Nitrazepam & 3.4 & 20.88 & 282 & MS-MS & 236 & 42 & 254 & 208 & 176 & & $75-500$ & $5+6$ \\
\hline Clonazepam & 4.5 & 22.39 & 316 & MS-MS & 270 & 42 & 288 & 251 & 223 & 176 & $85-500$ & $5+6$ \\
\hline OH-triazolam & 2.3 & 22.72 & 359 & MS-MS & 331 & 42 & 341 & 313 & 261 & & $95-500$ & $5+6$ \\
\hline Flunitrazepam & 5.4 & 22.96 & 314 & MS-MS & 268 & 42 & 286 & 193 & & & $85-500$ & $5+6$ \\
\hline$\alpha$-OH-alprazolam & 5.1 & 23.83 & 325 & MS-MS & 297 & 40 & 279 & 227 & 176 & & $85-500$ & 6 \\
\hline Alprazolam & 3.3 & 27.16 & 309 & MS-MS & 281 & 42 & 274 & 206 & & & $85-500$ & $7+8$ \\
\hline OH-ethylflurazepam & 3.9 & 27.44 & 333 & MS & $\mathrm{b}$ & $\mathrm{b}$ & 315 & 305 & 194 & & $50-500$ & $\mathrm{~b}$ \\
\hline Triazolam & 3.4 & 27.93 & 343 & MS-MS & 308 & 42 & 279 & 206 & 165 & & $90-500$ & $7+8$ \\
\hline Lorazepam & 6.3 & 28.07 & 321 & MS-MS & 303 & 30 & 335 & 275 & 166 & & $85-500$ & $7+8$ \\
\hline Brotizolam & 2.9 & 29.81 & 395 & MS-MS & 314 & 42 & 316 & 279 & 177 & & $105-500$ & $7+8$ \\
\hline Desalkylflurazepam & 3.9 & 29.95 & 289 & MS & b & b & 291 & 261 & 226 & 140 & $50-500$ & b \\
\hline Lormetazepam & 3.0 & 32.05 & 335 & MS-MS & 316 & 30 & 289 & 214 & 166 & & $90-500$ & $7+8$ \\
\hline Zolpidem & 2.0 & 5.35 & 308 & MS & b & b & 263 & 235 & & & $50-500$ & $\mathrm{~b}$ \\
\hline Desmethylmedazepam & 1.6 & 9.46 & 257 & MS & b & b & 240 & 193 & & & $50-500$ & b \\
\hline Norchlordiazepoxide & 8.1 & 9.88 & 287 & MS & $\mathrm{b}$ & b & 271 & 257 & 237 & 223 & $50-500$ & b \\
\hline Midazolam & 2.7 & 10.57 & 326 & MS & $\mathrm{b}$ & b & 286 & 270 & 163 & & $50-500$ & b \\
\hline Chlordiazepoxide & 0.4 & 12.49 & 300 & MS & $\mathrm{b}$ & b & 284 & 269 & 227 & & $50-500$ & $\mathrm{~b}$ \\
\hline Demoxepam & 14.7 & 18.31 & 287 & MS & b & b & 271 & 269 & 194 & & $50-500$ & $\mathrm{~b}$ \\
\hline Zopiclone & 60.5 & 17.47 & 277 & MS & b & b & 263 & 245 & 217 & & $50-500$ & b \\
\hline Desmethylclobazam & 32.1 & 21.73 & 287 & MS & $\mathrm{b}$ & $\mathrm{b}$ & 245 & 219 & & & $50-500$ & $\mathrm{~b}$ \\
\hline Clobazam & 34.4 & 25.04 & 301 & MS & $\mathrm{b}$ & $\mathrm{b}$ & 259 & 233 & 224 & & $50-500$ & $\mathrm{~b}$ \\
\hline Oxazepam & 3.4 & 27.45 & 287 & MS & $\mathrm{b}$ & $\mathrm{b}$ & 269 & 241 & 231 & 163 & $50-500$ & $\mathrm{~b}$ \\
\hline Temazepam & 3.3 & 29.97 & 301 & MS & $\mathrm{b}$ & $\mathrm{b}$ & 283 & 255 & 228 & & $50-500$ & $\mathrm{~b}$ \\
\hline Nordazepam & 1.2 & 32.35 & 271 & MS & b & b & 243 & 208 & 140 & & $50-500$ & $\mathrm{~b}$ \\
\hline Diazepam & 0.6 & 34.82 & 285 & MS & b & b & 257 & 228 & 212 & & $50-500$ & $\mathrm{~b}$ \\
\hline
\end{tabular}

Note: Ketazolam was excluded from the tested substances, due to rapid in vitro decomposition to diazepam: n.d.: not determined.

${ }^{a}$ Time intervals of the segments: segment 1: 0.00-8.25 min; segment 2: 8.25-15.00 min; segment 3: 15.00-17.75 min; segment 4: 17.75-19.75 min; segment 5: 19.75-21.50 min; segment 6: 21.50-25.25 min; segment 7: 25.25-29.00 min; segment 8: 29.00-37.00 min; segment 9: 37.00-45 min.

b Analysis in MS mode. 


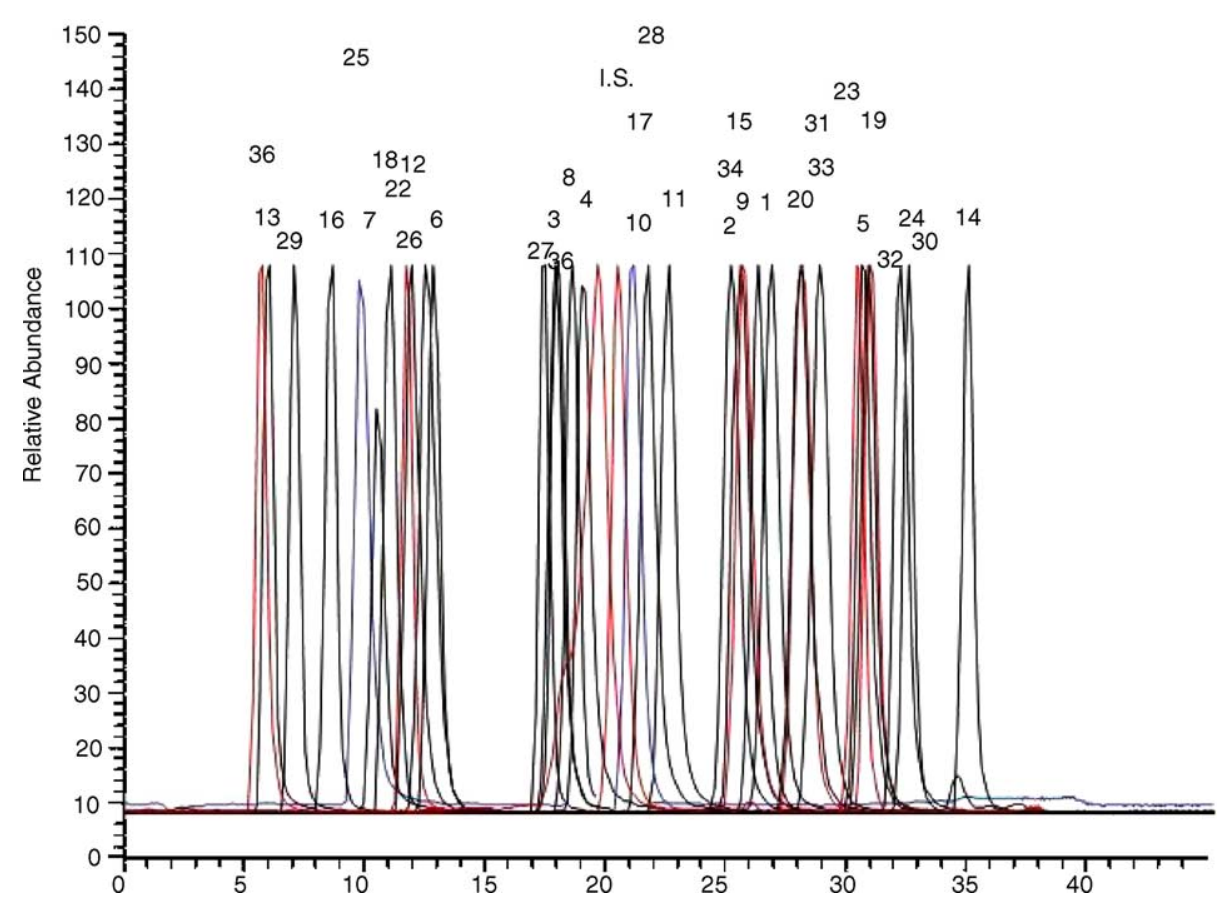

Fig. 1. Overlaid ion chromatograms of the tested benzodiazepines and benzodiazepine-like substances: (1) alprazolam; (2) $\alpha$-OH-alprazolam; (3) bromazepam; (4) OH-bromazepam; (5) brotizolam; (6) chloordiazepoxide; (7) norchlordiazepoxide; (8) demoxepam; (9) clobazam; (10) desmethylclobazam; (11) clonazepam; (12) acetamidoclonazepam; (13) aminoclonazepam; (14) diazepam; (15) flunitrazepam; (16) 7-aminoflunitrazepam; (17) $N$-desmethylflunitrazepam; (18) flurazepam (19) desalkylflurazepam; (20) OH-ethylflurazepam; (21) internal standard; (22) loprazolam; (23) lorazepam; (24) lormetazepam; (25) desmethylmedazepam; (26) midazolam; (27) 1-OH-midazolam; (28) nitrazepam; (29) acetamidonitrazepam; (30) nordazepam; (31) oxazepam; (32) temazepam; (33) triazolam; (34) OH-triazolam; (35) zolpidem; (36) zopiclone.

mother ion and collision energy, MS-MS fragment ions and scan segments are shown.

\subsection{Limit of detection, limit of quantification, linearity and recovery}

The LOD, LOQ, linearity and recovery on whole blood samples are presented in Table 2. The LOD ranges from $0.0001 \mathrm{mg} / \mathrm{l}$ for triazolam to $0.0068 \mathrm{mg} / \mathrm{l}$ for $\mathrm{OH}$ bromazepam, with the exception of norchlordiazepoxide (LOD $0.0126 \mathrm{mg} / \mathrm{l}$ ). In general, the LODs of compounds detected by MS-MS are lower than the LODs of substances submitted to MS. Taking into account therapeutic and toxic concentrations, linearity was studied in the range $0-0.200 \mathrm{mg} / \mathrm{l}, 0-0.500 \mathrm{mg} / \mathrm{l}, 0-1.000 \mathrm{mg} / \mathrm{l}, 0-2.000 \mathrm{mg} / \mathrm{l}$ or $0-5.000 \mathrm{mg} / \mathrm{l}$ in whole blood. Table 2 shows the regression coefficients, the slopes and the intercepts of the calibration curves in the defined concentration ranges. Linearity was satisfactory for all compounds.

The extraction recoveries for the different benzodiazepines in whole blood were between 60 and $91 \%$, with the exception of desmethylmedazepam (43\%), OH-bromazepam $(52 \%)$ and brotizolam $(114 \%)$.

Results were calculated without correction for the recovery of the internal standard; the relative standard deviation in the peak height of the internal standard was $40 \%$ in whole blood, compared to $7 \%$ in methanol. As a result, calibration curves that used relative responses were worse than calibration curves that used absolute responses. The concentration of methylbromazepam in the solution is unknown; we therefore obtained relative low responses and a relative high variation in the peak height of this compound. The extraction recovery may be problematic. No experiments have been performed to optimize the recovery of the internal standard.

\subsection{Specificity}

Specificity is defined as the ability of the bioanalytical method to measure a substance unequivocally and to discriminate between the analyte(s) and other components, that may be present [8]. In order to screen for interfering substances, three replicate analyses of six different blank blood samples were analyzed by using the developed LC-MS(MS) method. No interfering substances were detected.

\subsection{Accuracy and precision}

Accuracy and precision of four benzodiazepines, were calculated from six replicate analyses of a quality control serum sample. The mean, accuracy and precision of oxazepam, temazepam, nordazepam and diazepam are presented in Table 3. Intra-day precision for all benzodiazepines was calculated from the results of 10 replicate analyses at 
Table 2

Validation data on whole blood samples

\begin{tabular}{|c|c|c|c|c|c|c|c|c|}
\hline \multirow[t]{2}{*}{ Benzodiazepine } & \multirow{2}{*}{$\begin{array}{l}\text { LOD } \\
(\mathrm{ng} / \mathrm{ml})\end{array}$} & \multirow{2}{*}{$\begin{array}{l}\text { LOQ } \\
(\mathrm{ng} / \mathrm{ml})\end{array}$} & \multirow{2}{*}{$\begin{array}{l}y=a x+b \\
\left(R^{2}\right)\end{array}$} & \multirow{2}{*}{$\begin{array}{l}a, \text { slope } \\
(1 / \mathrm{mg})\end{array}$} & \multirow{2}{*}{$\begin{array}{l}b, \text { intercept } \\
\text { (a.u.) }\end{array}$} & \multirow{2}{*}{$\begin{array}{l}\text { Linearity range } \\
\text { tested }(\mathrm{mg} / \mathrm{l})\end{array}$} & \multicolumn{2}{|c|}{ Recovery } \\
\hline & & & & & & & $\%$ & $\overline{\mathrm{RSD} \%}$ \\
\hline Aminoclonazepam & 0.6 & 2.1 & 0.99812 & $4.52 \mathrm{E}+07$ & $-3.39 E+06$ & $0.002-5.0$ & 62 & 15 \\
\hline Acetamidonitrazepam & 0.4 & 1.4 & 0.99953 & $1.85 \mathrm{E}+07$ & $-4.51 \mathrm{E}+05$ & $0.001-5.0$ & 68 & 14 \\
\hline 7-Aminoflunitrazepam & 0.8 & 2.6 & 0.99476 & $1.74 \mathrm{E}+07$ & $-2.41 \mathrm{E}+05$ & $0.003-5.0$ & 62 & 17 \\
\hline Flurazepam & 1.6 & 5.5 & 0.98042 & $2.34 \mathrm{E}+06$ & $-3.41 \mathrm{E}+04$ & $0.006-1.0$ & 67 & 15 \\
\hline Loprazolam & 0.4 & 1.4 & 0.99537 & $9.77 \mathrm{E}+06$ & $1.72 \mathrm{E}+04$ & $0.001-0.5$ & 78 & 7 \\
\hline Acetamidoclonazepam & 0.2 & 0.9 & 0.99737 & $1.71 \mathrm{E}+07$ & $-1.73 \mathrm{E}+05$ & $0.001-1.0$ & 88 & 7 \\
\hline Bromazepam & 1.3 & 4.3 & 0.99876 & $1.72 \mathrm{E}+07$ & $-8.03 \mathrm{E}+05$ & $0.004-5.0$ & 84 & 15 \\
\hline OH-Bromazepam & 6.8 & 22.8 & 0.99793 & $3.58 \mathrm{E}+07$ & $-2.64 \mathrm{E}+05$ & $0.023-2.0$ & 52 & 26 \\
\hline$N$-Desmethylflunitrazepam & 0.2 & 0.7 & 0.99867 & $3.21 \mathrm{E}+07$ & $-1.82 \mathrm{E}+05$ & $0.001-1.0$ & 83 & 7 \\
\hline Nitrazepam & 0.2 & 0.7 & 0.99979 & $2.03 \mathrm{E}+07$ & $-9.33 \mathrm{E}+04$ & $0.001-1.0$ & 70 & 6 \\
\hline Clonazepam & 0.3 & 0.9 & 0.99970 & $2.89 \mathrm{E}+07$ & $-2.29 \mathrm{E}+04$ & $0.001-1.0$ & 72 & 6 \\
\hline OH-triazolam & 0.2 & 0.6 & 0.99703 & $1.40 \mathrm{E}+07$ & $-6.62 \mathrm{E}+03$ & $0.001-2.0$ & 87 & 6 \\
\hline Flunitrazepam & 0.2 & 0.7 & 0.99932 & $2.71 \mathrm{E}+07$ & $3.33 \mathrm{E}+04$ & $0.001-1.0$ & 75 & 6 \\
\hline$\alpha$-OH-alprazolam & 0.4 & 1.2 & 0.99924 & $3.20 \mathrm{E}+07$ & $-2.27 \mathrm{E}+05$ & $0.001-0.5$ & 74 & 6 \\
\hline Alprazolam & 0.4 & 1.3 & 0.99896 & $3.67 \mathrm{E}+07$ & $-1.11 \mathrm{E}+05$ & $0.001-0.5$ & 88 & 6 \\
\hline OH-ethylflurazepam & 1.8 & 5.9 & 0.99925 & $3.93 \mathrm{E}+07$ & $-3.98 \mathrm{E}+04$ & $0.006-0.5$ & 86 & 2 \\
\hline Triazolam & 0.1 & 0.4 & 0.99921 & $4.91 \mathrm{E}+07$ & $-2.32 \mathrm{E}+05$ & $0.0004-0.5$ & 78 & 5 \\
\hline Lorazepam & 0.2 & 0.6 & 0.99904 & $3.27 \mathrm{E}+07$ & $-2.41 \mathrm{E}+03$ & $0.001-1.0$ & 84 & 2 \\
\hline Brotizolam & 0.3 & 0.9 & 0.99906 & $2.19 \mathrm{E}+07$ & $-9.13 \mathrm{E}+04$ & $0.001-0.5$ & 114 & 8 \\
\hline Desalkylflurazepam & 0.9 & 2.9 & 0.99702 & $5.30 \mathrm{E}+07$ & $-4.13 \mathrm{E}+05$ & $0.003-2.0$ & 82 & 7 \\
\hline Lormetazepam & 0.6 & 1.8 & 0.99917 & $1.95 \mathrm{E}+07$ & $-2.26 \mathrm{E}+05$ & $0.002-5.0$ & 87 & 8 \\
\hline Desmethylmedazepam & 2.3 & 7.7 & 0.99477 & $2.19 \mathrm{E}+07$ & $-1.51 \mathrm{E}+05$ & $0.008-0.2$ & 43 & 29 \\
\hline Norchlordiazepoxide & 12.6 & 41.9 & 0.99846 & $3.46 \mathrm{E}+06$ & $-3.67 \mathrm{E}+04$ & $0.042-1.0$ & 60 & 17 \\
\hline Midazolam & 1.0 & 3.5 & 0.99607 & $6.86 \mathrm{E}+07$ & $-7.62 \mathrm{E}+05$ & $0.005-2.0$ & 65 & 8 \\
\hline Chlordiazepoxide & 1.7 & 5.8 & 0.99180 & $2.14 \mathrm{E}+07$ & $-5.99 \mathrm{E}+05$ & $0.006-2.0$ & 61 & 11 \\
\hline Demoxepam & 1.0 & 3.3 & 0.99888 & $2.99 \mathrm{E}+07$ & $-1.88 \mathrm{E}+04$ & $0.003-0.5$ & 91 & 7 \\
\hline Zopiclone & 4.6 & 15.3 & 0.99818 & $1.27 \mathrm{E}+07$ & $-1.92 \mathrm{E}+05$ & $0.015-1.0$ & 88 & 11 \\
\hline Desmethylclobazam & 2.9 & 9.6 & 0.99954 & $2.52 \mathrm{E}+07$ & $-3.32 \mathrm{E}+04$ & $0.010-0.5$ & 82 & 6 \\
\hline Clobazam & 0.6 & 2.0 & 0.99948 & $1.06 \mathrm{E}+08$ & $-2.89 \mathrm{E}+03$ & $0.002-1.0$ & 82 & 4 \\
\hline Oxazepam & 2.2 & 7.7 & 0.99952 & $3.02 \mathrm{E}+07$ & $-3.32 \mathrm{E}+04$ & $0.008-1.0$ & 83 & 5 \\
\hline Temazepam & 1.6 & 5.2 & 0.99974 & $3.70 \mathrm{E}+07$ & $-2.97 \mathrm{E}+05$ & $0.005-2.0$ & 81 & 6 \\
\hline Nordazepam & 4.3 & 14.3 & 0.99871 & $6.01 \mathrm{E}+07$ & $-2.38 \mathrm{E}+05$ & $0.014-1.0$ & 76 & 5 \\
\hline Diazepam & 4.0 & 13.3 & 0.99898 & $7.23 \mathrm{E}+07$ & $-1.52 \mathrm{E}+04$ & $0.013-1.0$ & 73 & 4 \\
\hline
\end{tabular}

LOD: limit of detection; LOQ: limit of quantification; RSD: relative standard deviation. Note 1: OH-midazolam was not determined due to insufficient substance available. Note 2: zolpidem was excluded because the results were not satisfactory.

three concentration levels. Table 4 shows the intra-day precision for all compounds.

\section{Discussion}

In literature, several methods for the analysis of benzodiazepines are described, generally consisting of GC-MS methods as well as methods using HPLC-DAD [9-12]. However, high-performance liquid chromatography with mass spectrometric detection is becoming increasingly the method of choice for simultaneous quantification and confirmation of many polar and/or chemically instable drugs, including benzodiazepines [13-17]. The analysis of benzodiazepines can be performed by using APCI-LC-MS [7,18,19] as well as electro spray ionization (ESI)-LC-MS [20,21].

The LC-MS(MS) method described in this article allows us to analyze 33 benzodiazepines, metabolites and benzodiazepine-like substances in whole blood and to reach detection limits lower than those observed with conventional LC-DAD or GC-MS methods. Low dose as well as high dose benzodiazepines can be determined in one run. The results of

Table 3

Precision and accuracy

\begin{tabular}{lllrl}
\hline Compound & $\begin{array}{l}\text { Quality control sample KKGT 2003, } \\
\text { The Netherlands concentration in } \\
\text { serum }(\mathrm{mg} / \mathrm{l})\end{array}$ & $\begin{array}{l}\text { Analytical results mean, } \\
n=6(\mathrm{mg} / \mathrm{l})\end{array}$ & Accuracy \% deviation & Precision intra-day RSD (\%) \\
\hline Oxazepam & 0.5063 & 0.4720 & -3.4 & 3.5 \\
Temazepam & 0.1044 & 0.1067 & 2.2 & 5.5 \\
Nordazepam & 0.2107 & 0.2298 & 2.1 & 3.6 \\
Diazepam & 0.3445 & 0.4139 & 20.1 & 5.6 \\
\hline
\end{tabular}


Table 4

Precision of benzodiazepines in whole blood samples

\begin{tabular}{|c|c|c|c|}
\hline Benzodiazepine & $\begin{array}{l}0.01 \mathrm{mg} / \mathrm{l} \\
\text { (RSD\%) }\end{array}$ & $\begin{array}{l}0.1 \mathrm{mg} / \mathrm{l} \\
(\mathrm{RSD} \%)\end{array}$ & $\begin{array}{l}1 \mathrm{mg} / 1 \\
(\mathrm{RSD} \%)\end{array}$ \\
\hline Aminoclonazepam & 0 & 8 & 10 \\
\hline Acetamidonitrazepam & 3 & 22 & 10 \\
\hline 7-Aminoflunitrazepam & 3 & 18 & 12 \\
\hline Flurazepam & 7 & 23 & 10 \\
\hline Loprazolam & 35 & 12 & 5 \\
\hline Acetamidoclonazepam & 3 & 15 & 5 \\
\hline OH-midazolam & n.d. & n.d. & n.d. \\
\hline Bromazepam & 3 & 7 & 10 \\
\hline OH-Bromazepam & 17 & 30 & 18 \\
\hline$N$-Desmethylflunitrazepam & 5 & 10 & 5 \\
\hline Nitrazepam & 5 & 17 & 4 \\
\hline Clonazepam & 8 & 13 & 5 \\
\hline OH-triazolam & 9 & 15 & 4 \\
\hline Flunitrazepam & 11 & 11 & 5 \\
\hline$\alpha$-OH-alprazolam & 4 & 14 & 4 \\
\hline Alprazolam & 9 & 15 & 4 \\
\hline OH-ethylflurazepam & 10 & 11 & 2 \\
\hline Triazolam & 4 & 14 & 4 \\
\hline Lorazepam & 4 & 14 & 2 \\
\hline Brotizolam & 9 & 13 & 6 \\
\hline Desalkylflurazepam & 6 & 11 & 5 \\
\hline Lormetazepam & 4 & 13 & 6 \\
\hline Desmethylmedazepam & 11 & 35 & 20 \\
\hline Norchlordiazepoxide & 8 & 14 & 12 \\
\hline Midazolam & 3 & 11 & 5 \\
\hline Chlordiazepoxide & 3 & 14 & 8 \\
\hline Demoxepam & 11 & 16 & 5 \\
\hline Zopiclone & 8 & 12 & 8 \\
\hline Desmethylclobazam & 8 & 13 & 4 \\
\hline Clobazam & 8 & 12 & 3 \\
\hline Oxazepam & 14 & 14 & 3 \\
\hline Temazepam & 5 & 16 & 4 \\
\hline Nordazepam & 8 & 10 & 3 \\
\hline Diazepam & 16 & 11 & 3 \\
\hline
\end{tabular}

RSD: relative standard deviation: n.d.: not determined due to insufficient substance available.

this study show the advantages of LC-MS(MS): higher specificity, lower detection limits, simultaneous measurement of many substances as well as satisfactory validation characteristics. The alternation of MS and MS-MS detection allows us to measure high and low blood levels of different substances simultaneously; no interference has been noticed.

Extraction was performed with pre-buffered columns at $\mathrm{pH}$ 9. This is in agreement with other methods, where high recoveries were found by adjusting the $\mathrm{pH}$ to alkaline before extraction [7]. The extraction procedure we use allows us to reach lower limits of detection by concentrating the compounds by a factor 10 . The low limits of detection make this method suitable for the analysis of benzodiazepines in whole blood as well as in other biological fluids such as oral fluid. This may be an advantage in research projects concerning road-side drug testing.

In other methods described, the $\mathrm{pH}$ of the mobile phase varied from acidic to slightly alkaline $[7,11,15]$. In our protocol, best separation was achieved by using a solution at $\mathrm{pH}$ 3.
The range of linearity of most benzodiazepines was satisfactory, with respect to the therapeutic range for forensic and clinical purposes. In case of (suspected) concentrations higher than the range of linearity, repeated analysis is required after dilution. For most compounds, extraction recoveries were more than $60 \%$.

For some benzodiazepines and metabolites, extraction recoveries were relatively low. For those substances, adding a suitable internal standard or optimizing the extraction procedure may improve the results. However, an internal standard for each benzodiazepine, metabolite or benzodiazepinelike substance, is impractical and sometimes not available. For compounds having a relatively low recovery or higher relative standard deviation, our method gives semiquantitative results. Accuracy has been determined for oxazepam, temazepam, nordazepam and diazepam and was found to be satisfactory. A variation of $20 \%$ is generally considered as acceptable [22]. Results may be biased by matrix effects since the quality control sample was drug spiked serum, whereas results were calculated on calibration curves in whole blood samples. Intra-day precision of the benzodiazepines in the quality control sample and in the spiked whole blood samples was sufficient for forensic purposes [22]. Unfortunately, quality control blood samples were not available for all tested substances.

Inter-day precision was not determined: in forensic case work, calibration curves are included in each analysis.

\section{Conclusions}

This sensitive and selective method offers the opportunity for simultaneous screening and quantification of almost all benzodiazepines and benzodiazepine-like substances, which are available in The Netherlands and that are relevant in clinical and forensic cases. Low dose as well as high dose benzodiazepines can be measured simultaneously, with low detection limits, low limits of quantification and satisfactory validation characteristics.

\section{References}

[1] Goodman \& Gilman's The Pharmacological Basis of Therapeutics, IXth ed., 1996.

[2] O.H. Drummer, Benzodiazepines-effects on human performance and behaviour, Forensic Sci. Rev. 14 (1-2) (2002).

[3] Informatorium Medicamentorum 2003, Koninklijke Nederlandse Maatschappij ter bevordering der Pharmacie, Den Haag.

[4] M.J. Panneman, W.G. Goettsch, P. Kramarz, R.M. Herings, Drugs Aging 20 (11) (2003) 833.

[5] C.F. George, C.D. Bayliff, Drugs 63 (4) (2003) 379.

[6] F. Barbone, A.D. McMahon, P.G. Davey, A.D. Morris, I.C. Reid, D.G. McDevitt, T.M. MacDonald, Lancet 352 (1998) 1331.

[7] M.J. Bogusz, R.-D. Maier, K.-D. Krúger, W. Frúchtnicht, J. Chromatogr. B 713 (1998) 361.

[8] F.T. Peters, H.H. Maurer, Accred. Qual. Assur. 7 (2002)441. 
[9] S. Pirnay, I. Ricordel, D. Libong, S. Bouchonnet, J. Chromatogr. A 954 (2002) 235.

[10] A. Sioufi, J.P. Dubois, J. Chromatogr., Biomed. Appl. 531 (1990) 459.

[11] H. Inoue, Y. Maeno, M. Iwasa, R. Matoba, M. Nagao, Forensic Sci. Int. 113 (2000) 367.

[12] O.H. Drummer, J. Chromatogr. B 713 (1998) 201.

[13] H.H. Maurer, J. Chromatogr. B 713 (1998) 3.

[14] A. Miki, M. Tatsuno, M. Katagi, M. Nishikawa, H. Tsuchihashi, J. Anal. Toxicol. 26 (2002) 87.

[15] K. Heinig, J. Henion, J. Chromatogr. B 732 (1999) 445.

[16] A.M.A. Verweij, M.L. Hordijk, P.J.L. Lipman, J. Chromatogr. B 686 (1996) 27.
[17] M.J. Bogusz, J. Chromatogr. B 748 (2000) 3.

[18] J. Darius, P. Banditt, J. Chromatogr. B 738 (2000) 437.

[19] H.H. Maurer, T. Kraemer, C. Kratzsch, F.T. Peters, A.A. Weber, Ther. Drug Monit. 24 (1) (2002) 117.

[20] D.J. Crouch, D.E. Rollins, D.V. Canfield, D.M. Andrenyak, J.E. Schulties, J. Anal. Toxicol. Vol23 (1999)479.

[21] N. Jourdil, J. Bessard, F. Vincent, H. Eysseric, G. Bessard, Analyt. Technol. Biomed. Life Sci. 788 (2) (2003)207.

[22] A.C. Moffat, M.D. Osselton, B. Widdop (Ed.), Clarke's analysis of drugs and poisons, Quality Control and Assessment, third ed., 2004, pp. 161-172 (Chapter 11). 